\title{
Negligible transcriptome and metabolome alterations in RNAi insecticidal maize against Monolepta hieroglyphica
}

\author{
Xiaolei Zhang ${ }^{1} \cdot$ Ruiying Zhang ${ }^{1} \cdot$ Liang $^{\mathrm{Li}^{2}}$ - Yang Yang ${ }^{1} \cdot$ Yijia Ding $^{1} \cdot$ Haitao Guan ${ }^{1} \cdot$ Xiaoqin Wang $^{1}$. \\ Aihong Zhang ${ }^{3} \cdot$ Hongtao Wen $^{1}$ (i)
}

Received: 7 July 2020 / Accepted: 17 August 2020 / Published online: 31 August 2020

(c) The Author(s) 2020

\begin{abstract}
Key message RNAi-based genetically modified maize resistant to Monolepta hieroglyphica (Motschulsky) was demonstrated with negligible transcriptome and metabolome alterations compared to its unmodified equivalent.

Abstract As one of the most prevalent insect pests afflicting various crops, Monolepta hieroglyphica (Motschulsky) causes severe loss of agricultural and economic productivity for many years in China. In an effort to reduce damages, in this study, an RNA interference (RNAi)-based genetically modified (GM) maize was developed. It was engineered to produce MhSnf7 double-stranded RNAs (dsRNAs), which can suppress the Snf7 gene expression and then lead M. hieroglyphica to death. Field trail analysis confirmed the robustly insecticidal ability of the MhSnf7 GM maize to resist damages by M. hieroglyphica. RNA sequencing analysis identified that only one gene was differentially expressed in the MhSnf7 GM maize compared to non-GM maize, indicating that the transcriptome in MhSnf7 GM maize is principally unaffected by the introduction of the MhSnf7 dsRNA expression vector. Likewise, metabolomics analysis identified that only 8 out of 5787 metabolites were significantly changed. Hence, the integration of transcriptomics and metabolomics demonstrates that there are negligible differences between MhSnf7 GM maize and its unmodified equivalent. This study not only presents a comprehensive assessment of cellular alteration in terms of gene transcription and metabolite abundance in RNAi-based GM maize, but also could be used as a reference for evaluating the unintended effect of GM crops.
\end{abstract}

Keywords Transcriptome $\cdot$ Metabolome $\cdot$ RNAi insecticidal maize $\cdot$ Monolepta hieroglyphica (motschulsky) $\cdot$ Unintended effect

Communicated by Günther Hahne.

Electronic supplementary material The online version of this article (https://doi.org/10.1007/s00299-020-02582-4) contains supplementary material, which is available to authorized users.

Hongtao Wen

wen0891@163.com

1 Quality and Safety Institute of Agricultural Products, Heilongjiang Academy of Agricultural Sciences, Harbin 150086, China

2 Biotechnology Research Institute, Chinese Academy of Agricultural Sciences, Beijing 100081, China

3 Beijing DaBeiNong Biotechnology Co., Ltd., Beijing 100080, China

\section{Introduction}

As one of the major maize producers in the world, China has made outstanding contributions to global grain production. In 2018, the agricultural land dedicated to Chinese maize production increased to 42.13 million hectares. The total yield of maize was 257.17 million tons and accounted for $22.9 \%$ of global production (China Statistical Yearbook 2019). The rapid increase of Chinese maize production has promoted the stable development of the global agricultural economy. Currently, however, maize production has been significantly hampered by insect pests such as Monolepta hieroglyphica. As a member of the order Coleoptera, $M$. hieroglyphica breeds quickly and has gradually expanded its range in China since 2008 ( $\mathrm{Li}$ et al. 2016; Liu et al. 2016). In addition to maize, $M$. hieroglyphica also damages soybean, peanut, and other crops. The broad host and geographic range coupled with high fecundity has positioned 
M. hieroglyphica as a major factor responsive for the drastic reduction in agricultural productivity with significant economic impact (Chen et al. 2016; Shi et al. 2017; Yan et al. 2019). At the present time, it is still a severe problem.

GM technology affords the most direct and effective way to combat a variety of bacterial, fungal, and insect pests that plague modern agriculture. For decades, GM crops such as maize (Wang et al. 2018), rice (Shen et al. 2019), tomato (Luan et al. 2016), cotton (Ni et al. 2017) and potato (Bagri et al. 2018) have been developed in response to a variety of agricultural problems and has resulted in crops with improved resistance to insects, disease, and environmental stress. GM crops, however, have been the subject of intense scrutiny regarding safety concerns especially in the context of public health (Schiemann et al. 2019). Although there has been no direct evidence to demonstrate any deleterious effects from GM crops on human health or the environment, it is essential that all GM safety issues are addressed including potential unintended effects prior to introducing GM crops or products for agricultural use (FAO/WHO 2000).

The so-called "Omics" technologies, including transcriptomics, proteomics and metabolomics, have been used not only for general biological analysis, but also more recently for safety assessment of transgenic plants (Zhou et al. 2012; Lambirth et al. 2015; Gayen et al. 2016; Rao et al. 2016; Van Emon 2016; Li et al. 2017; Abdullah et al. 2018; Ning et al. 2018; Peng et al. 2018; Wang et al. 2018). These methods allow for accurate detection of differentially expressed genes, proteins and metabolites relevant to a given plant phenotype as well as nutritional and toxicological characteristics (Harrigan and Chassy 2012). Besides, the analyses using these technologies are hypothetically stringent, which satisfy the unbiased assessment of any unintended effects (Rao et al. 2016). In this study, we utilized transcriptomics and metabolomics technologies to compare the cellular differentiation between RNAi-based GM maize and non-GM maize. Our data reveal that there is negligible differences between GM and non-GM plants, supporting the biosafety of the MhSnf7 GM maize.

\section{Materials and methods}

\section{Molecular cloning and genetic transformation}

Total RNA from larvae of $M$. hieroglyphica was extracted by using Omega Plant RNA kit (Omega Bio-Tek, USA). Poly-oligo dT magnetic beads were used to extract mRNA from total RNA. cDNA was synthetized from the extracted mRNA by using Superscript II reverse transcritase kit (Invitrogen, USA). The primers were designed based on the Snf7 gene sequence (Genbank ID XM_028287710.1) in National Center for Biotechnology Information (NCBI) database. The
Table 1 Primers used for target fragments cloning

\begin{tabular}{ll}
\hline Primer name & Primer sequence $\left(5^{\prime}-3^{\prime}\right)$ \\
\hline Snf 7-P1F & CTAGTCCTGGGGAGGCTATT \\
Snf 7-P1R & TCATCTTAGATGGGTGATTTC \\
\hline
\end{tabular}

Table 2 Primers used for dsRNA detection

\begin{tabular}{ll}
\hline Primer name & Primer sequence $\left(5^{\prime}-3^{\prime}\right)$ \\
\hline Snf 7-P3F & AGAGGAATACACCTTACTAGC \\
Snf 7-P3R & TGTAAGAGTTCCATCTATTTGC \\
qRT-CUL-F & GAAGAGCCGCAAAGTTATGG \\
qRT-CUL-R & ATGGTAGAAGTGGACGCACC \\
\hline
\end{tabular}

target fragments were amplified from the cDNA library with the following primer sets (Table 1) and a standard shuttle PCR protocol $\left(95^{\circ} \mathrm{C}\right.$ for $3 \mathrm{~min}, 94^{\circ} \mathrm{C}$ for $30 \mathrm{~s}$ and $55^{\circ} \mathrm{C}$ for $30 \mathrm{~s}, 40$ cycles). The target fragment, promoter and terminator were inserted into T-DNA to form expressing vector based on conventional molecular biological methods. The presence of the target fragment was confirmed by colony PCR after the vector was transformed into Agrobacterium.

Calli of Zea mays L. Zong 31 line were subjected to coculture with Agrobacterium harboring plasmid. The transformation process followed a published procedure (Hiei et al. 1994). Regenerated $T 0$ plants were grown in a growth chamber at a temperature of $24 \pm 1{ }^{\circ} \mathrm{C}$ with $16 \mathrm{~h}$ light and $8 \mathrm{~h}$ dark at a relative humidity of $80 \%$.

To detect the expression of dsRNA in plant, cDNA library was obtained from the leaves of GM maize $F_{2}$ inbred line mRNA. The dsRNA was confirmed by specific PCR using the following primer sets (Table 2). The PCR reaction program was as follows: $95{ }^{\circ} \mathrm{C}$ for $3 \mathrm{~min}, 94{ }^{\circ} \mathrm{C}$ for $30 \mathrm{~s}$ and $55^{\circ} \mathrm{C}$ for $30 \mathrm{~s}, 40$ cycles.

\section{Chamber trait analysis}

The resistance of MhSnf7 GM maize to M. hieroglyphica was evaluated using a bioassay method. Ten larvae of $M$. hieroglyphica (younger than $24 \mathrm{~h}$ ) were added to each culture dish containing corn whorl leaves (3 leaf stage) and cultured in a climate-controlled chamber with the following conditions: $24 \pm 2{ }^{\circ} \mathrm{C}, 70-80 \%$ relative humidity and $0 \mathrm{~h}$ day $/ 24 \mathrm{~h}$ night photoperiod. Two days after inoculation, the proportion of living larvae was determined. Statistical analysis was performed using the Student's $t$ test.

\section{Transcriptome analysis}

Four MhSnf7 GM (5-6 leaf stage) and four non-GM maize plants (5-6 leaf stage) were randomly selected to serve as 
four biological replicates. Total RNA from maize leaves was extracted using Omega Plant RNA kit (Omega Bio-Tek, USA) and analyzed by agarose gel electrophoresis. Polyoligo dT magnetic beads were used to extract mRNA from total RNA. The transcriptome sequence library was constructed using the NEBNext ${ }^{\circledR}$ Ultra ${ }^{\mathrm{TM}}$ RNA LibraryPrep Kit for Illumina ${ }^{\circledR}$ (NEB, USA) following the manufacturer's instructions. The RNA-seq library was sequenced on the Illumina Hiseq 2000 platform. Clean reads were obtained by removing adapter sequences and omitting reads containing more than $10 \%$ unknown nucleotides or with low quality (containing more than $50 \%$ bases with $Q$-score $\leq 20$ ).

Gene expression levels were evaluated in fragments per kilobase million (FPKM) based on the number of fragments mapped to the reference sequence. Differential expression analysis was performed using the DEGseq R package. Genes with an adjusted false discovery rate $(\mathrm{FDR})<0.05$ and $\log _{2}$ fold changel $>1$ were scored as differentially expressed.

\section{UPLC-MS/MS metabolome analysis}

Metabolites were extracted from $50 \mathrm{mg}$ of $M h S n f 7 \mathrm{GM}$ and non-GM maize leaves from eight biological replicates using the solvent: $40 \%$ acetonitrile, $40 \%$ methanol, $20 \%$ water and $1 \mathrm{ng} / \mu \mathrm{L}$ 2-chloro-L-phenylalanine (internal standard). The samples were then vortexed for $30 \mathrm{~s}$, homogenized at $45 \mathrm{~Hz}$ for $4 \mathrm{~min}$, treated with ultrasound for $5 \mathrm{~min}$ in an ice-water bath, and stored $-20^{\circ} \mathrm{C}$ for $1 \mathrm{~h}$. The homogenate was then centrifuged at $13,500 \times g$ for $15 \mathrm{~min}$ at $4{ }^{\circ} \mathrm{C}$. The resulting supernatants were transferred to vials and stored at $-80{ }^{\circ} \mathrm{C}$ until analysis.

UPLC-MS/MS analyses were performed using a UHPLC system (1290, Agilent Technologies) with a UPLC HSS T-3 column $(2.1 \times 100 \mathrm{~mm}, 1.8 \mu \mathrm{m})$ coupled to Q Exactive (Orbitrap MS, Thermo). The mobile phase A contained $0.1 \%$ formic acid and water. The mobile phase B was acetonitrile. The elution procedure parameters were as follows: $0 \mathrm{~min}, 1 \%$ B; 1 min, 1\% B; 8 min, 99\% B; 10 min, 99\% B; $10.1 \mathrm{~min}, 1 \%$ $\mathrm{B} ; 12 \mathrm{~min}, 1 \% \mathrm{~B}$ with a flow rate of $0.5 \mathrm{~mL} / \mathrm{min}$. The injection volume was $3 \mu \mathrm{L}$. For mass spectrometry, ESI source conditions were set as following: sheath gas flow rate as $45 \mathrm{Arb}$, aux gas flow rate as $15 \mathrm{Arb}$, capillary temperature $320^{\circ} \mathrm{C}$, full ms resolution as 70,000 , MS/MS resolution as 17,500 , collision energy as $20 / 40 / 60 \mathrm{eV}$ in NCE model, spray voltage as $3.8 \mathrm{kV}$.

ProteoWizard software (version 3.0.4472) and R package XCMS (version 3.2) were used to conduct the MS raw data converting and processing. OSI-SMMS (version 1.0, Dalian ChemDataSolution Information Technology Co. Ltd.) was used for peak annotation. The data involving the sample name, peak number and normalized peak area were analyzed using SIMCA14.1 software package (V14.1, Sartorius Stedim Data Analytics AB, Umea, Sweden) for principal component analysis (PCA) and orthogonal projections to latent structures-discriminate analysis (OPLSDA). Metabolites with variable importance in the projection (VIP) values exceeding 1 and a false discovery rate $(F D R)<0.05$ were considered differentiated.

\section{Results}

\section{Molecular characterization of MhSnf7 GM maize}

The vector DBN11048 containing the target reverse complementary nucleotide sequence of $M h S n f 7$ was constructed as shown in Fig. 1. To assay for transgene integration after transformation, specific PCR was performed for simultaneous detection and the presence of stably integrated T-DNA in leaf genome was verified (Fig. S1). The third-generation sequencing technology detected that the vector was integrated into the tested maize 9 chromosome with single copy.

The expression of the MhSnf7 dsRNA in leaf, stem and root tissues was determined by fluorescence quantitative PCR. A dissociation curve showing a single peak at the melting temperature expected for that amplicon suggests specific amplification. The results showed that the MhSnf7 dsRNA was highly expressed in all three tissues of GM maize, while there was no expression in the non-GM control (Fig. 2).

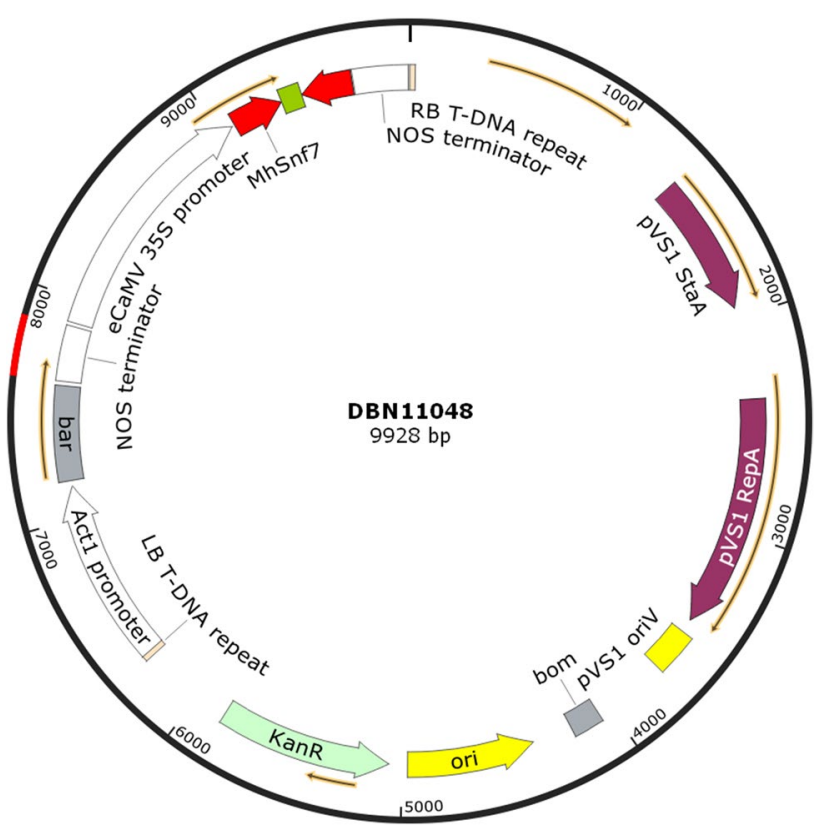

Fig. 1 Schematic map of the MhSnf7 dsRNA expression vector DBN11048. The vector contains eCaMV 35S promoter, which promotes the MhSnf7 dsRNA with a high expression level. The selection marker is bar gene 


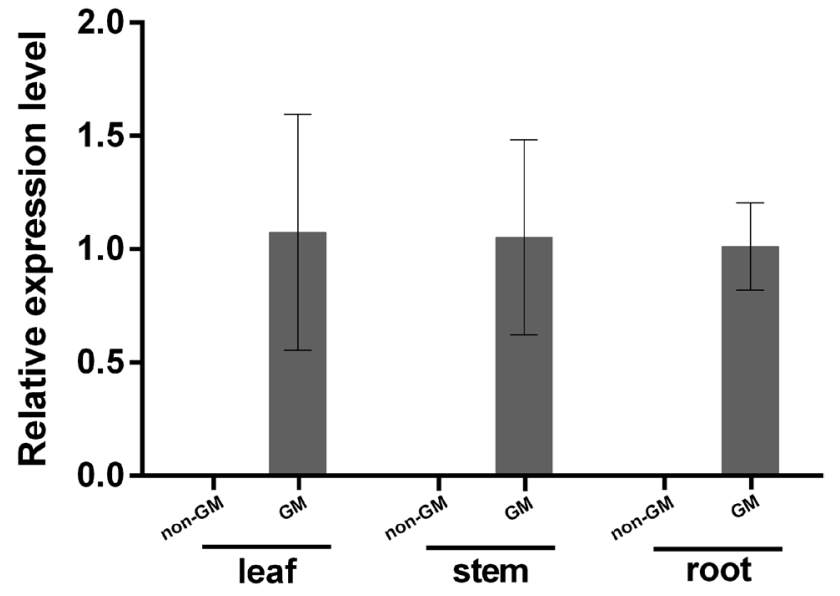

Fig. 2 Relative expression analysis of $M h S n f 7$ dsRNA detected by qRT-PCR in the tissues of GM maize and non-GM maize. Mean \pm SE was calculated for each tissue type. The values shown in this figure are the averages of three independent experiments. Error bars represent the SD $(n=3)$ of relative expression levels of MhSnf7 dsRNA

\section{Chamber trait analysis of MhSnf7 GM maize}

Newly hatched larvae of $M$. hieroglyphica were fed with young leaves from MhSnf7 GM and non-GM maize, respectively. After 16 days, the number of dead M. hieroglyphica larvae that had been fed on MhSnf7 GM leaves was significantly greater compared to non-GM maize $(P<0.0001)$. The mortality rate (dead larvae/total larvae $\times 100 \%)$ on day 16 for the GM maize was approximately fourfold greater than that for non-GM maize (Fig. 3). This result demonstrates that the MhSnf7 GM

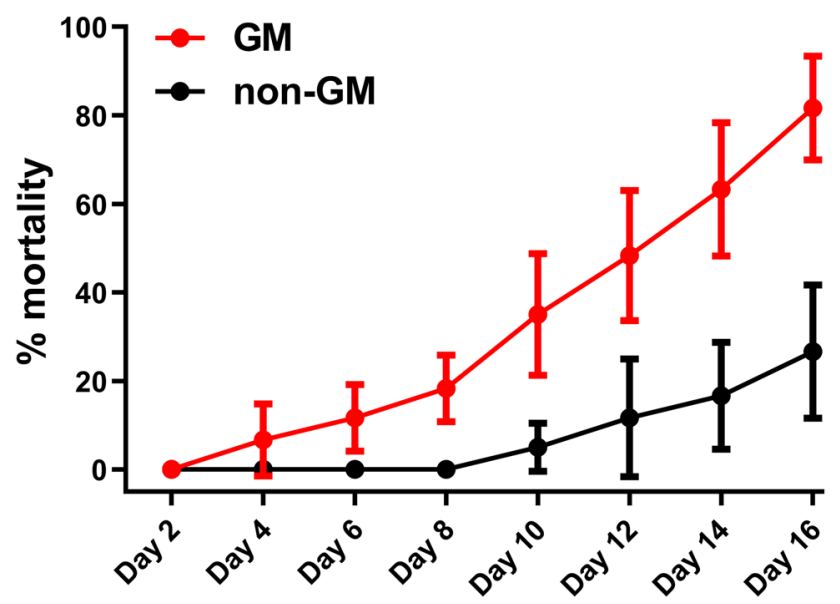

Fig. 3 Insecticidal field trail analysis of MhSnf7 GM maize. M. hieroglyphica larvae fed on GM maize and non-GM maize at time points as the $\mathrm{x}$-axis. The mortalities as the $\mathrm{y}$-axis are shown in red line and black line, respectively. Error bars represent the mortality SD $(n=10)$ of $M$. hieroglyphica larvae maize exhibits robust insecticidal capacity by demising M. hieroglyphica larvae.

\section{Transcriptome analysis of MhSnf7 GM and non-GM maize}

RNA-seq libraries prepared from MhSnf7 GM and nonGM maize leaves were sequenced individually using the Illumina Hiseq 2000 platform. The high-quality clean reads from the two groups after raw read quality filtering were obtained (Table 3). Using the maize Ensembl release 34 AGPv4 as the reference genome, the average mapped ratios were $82.18 \%$ for $M h S n f 7$ GM group and $82.60 \%$ for non-GM maize group, respectively. Quality analysis showed that the two groups had an average of $55.61 \%$ and $55.65 \% \mathrm{GC} \mathrm{( \% )} \mathrm{content} \mathrm{of} \mathrm{clean} \mathrm{reads,} 98.98 \%$ and $98.94 \%$ of Q20, and $96.71 \%$ and $96.61 \%$ of Q30, respectively. These data presented a high-quality sequencing, which can satisfy the subsequent analyses. Raw transcriptome sequences data have been deposited at NCBI Sequence Read Archive (SRA) under accession PRJNA546119.

An unsupervised model of PCA analysis was conducted, which can provide a natural and global informative look at the relationships between groups and would be used to formulate an initial biological conclusion (Worley and Powers 2013). The PCA analysis showed that the samples could not be separated, indicating that MhSnf7 GM and non-GM maize groups were very similar at the transcriptional level (Fig. 4a). Under the threshold of FDR $<0.05$ and $\log _{2}$ fold changel $>1$, we could identify that out of 31,635 detected genes, only one gene was differentially expressed (Fig. 4b). This result demonstrates that there is negligible transcriptome variation between the MhSnf7 GM and non-GM maize.

Table 3 RNA-sequencing and quality analysis results

\begin{tabular}{llllll}
\hline Sample & $\begin{array}{l}\text { HQ clean } \\
\text { reads num- } \\
\text { ber }\end{array}$ & Mapping ratio & Q20 & Q30 & GC \\
\hline$T-1$ & 50077892 & $82.48 \%$ & $98.96 \%$ & $96.66 \%$ & $55.32 \%$ \\
$T-2$ & 52977600 & $82.35 \%$ & $98.95 \%$ & $96.64 \%$ & $55.44 \%$ \\
$T-3$ & 22649082 & $81.14 \%$ & $99.01 \%$ & $96.80 \%$ & $55.76 \%$ \\
$T-4$ & 45179534 & $82.76 \%$ & $98.98 \%$ & $96.72 \%$ & $55.74 \%$ \\
CK-1 & 47901628 & $82.33 \%$ & $98.97 \%$ & $96.69 \%$ & $56.26 \%$ \\
CK-2 & 52459298 & $82.24 \%$ & $98.93 \%$ & $96.59 \%$ & $55.82 \%$ \\
CK-3 & 55196970 & $82.95 \%$ & $98.97 \%$ & $96.67 \%$ & $56.06 \%$ \\
CK-4 & 45438342 & $82.86 \%$ & $98.88 \%$ & $96.49 \%$ & $54.46 \%$ \\
\hline
\end{tabular}


a

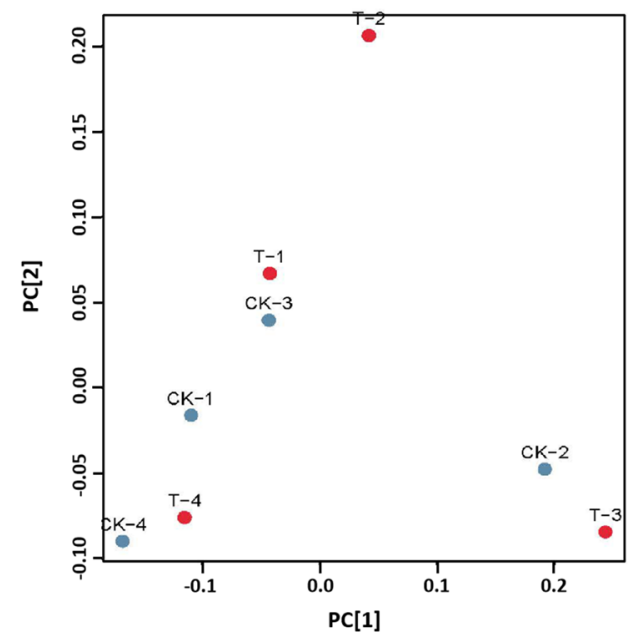

Fig. 4 Differentially expressed genes analysis in GM and non-GM maize. a PCA analysis indicates the similarity of RNA-Seq datasets between the two groups. b Volcano plot with $-\log _{10}$ (FDR-value) from the $t$ test as the $\mathrm{y}$-axis and $\log _{2}$ (fold change) as the $\mathrm{x}$-axis. The

\section{Metabolome analysis of MhSnf7 GM and non-GM maize}

UPLC-MS/MS was performed on the metabolic extracts prepared from GM and non-GM maize leaves to address the changes in metabolome. PCA analysis showed that there was no marked trend of segregation between the two groups, indicative of the identical pattern of metabolome between MhSnf7 GM and non-GM maize (Fig. 5a).

To maximize the discrimination between the two groups, we used OPLS-DA supervised multivariate data analysis to elucidate the different metabolic patterns. The score plot showed all samples were lying inside the $95 \%$ confidence interval (Hotelling's $T$-squared ellipse) with clear separation and discrimination between the pairwise groups (Fig. 5b). The $R^{2} Y$ and $Q^{2}$ intercept values of the permutation test were 0.95 and -0.47 , respectively (Fig. 5c). The $R^{2} Y$ close to 1 with low $Q^{2}$ indicated that the established model had no overfitting phenomenon and can be used in subsequent analyses.

In total, 5787 metabolites were detected after preprocessing the raw data. The dataset of metabolome profiles included 172 compounds with known identity (Table S1). The metabolites identified as statistically significant were set with the cutoff of VIP $>1$ and FDR $<0.05$. Under this criteria, eight differential metabolites were determined between MhSnf7 GM and non-GM maize (Table 4). Among these metabolites, five and three were b

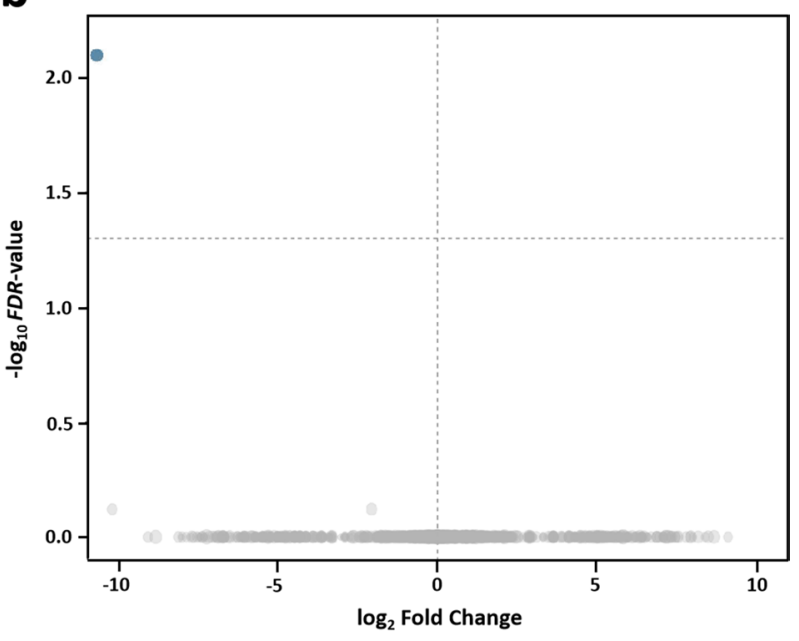

blue dot represents down-regulated gene with $\mid \log _{2}$ fold changel $>1$ and FDR $<0.05$, and the gray dots represent non-differentially expressed genes

down-regulated or up-regulated in GM maize relative to non-GM maize, respectively (Fig. 6).

\section{Discussion}

Over the past decades, RNAi techniques have emerged as an eco-friendly, efficient, and reliable platform for the development of GM insecticidal plants (Mao et al. 2007; Bachman et al. 2013; Ni et al. 2017; Poreddy et al. 2017; Fu et al. 2019; Darsan Singh et al. 2019). These plants harbor doublestranded RNAs (dsRNAs) that can target and suppress mRNA levels through the RNAi pathway and lead to insect morbidity or mortality (Zhang et al. 2017). The interference sequence of exogenous genes inserted into plant genomic DNA can form a hairpin structure, which is recognized and degraded by Dicer after transcription (Vazquez et al. 2010). The inserted sequence will not be translated into protein. Hence, RNAibased GM plants hold the attractive potential for not only improving crop quality and yield, but also avoiding the accumulation of exogenous proteins, and ultimately guaranteeing high biological safety. The first RNAi-based insect control trait expressing $D v S n f 7$ dsRNA was found to protect maize roots from feeding damage by the western corn rootworm (Diabrotica virgifera virgifera; WCR) (Baum et al. 2007; Bolognesi et al. 2012; Bachman et al. 2016). This discovery has enabled Monsanto Co. to successfully develop and commercialize the first RNAi insecticidal maize MON 87,411. 


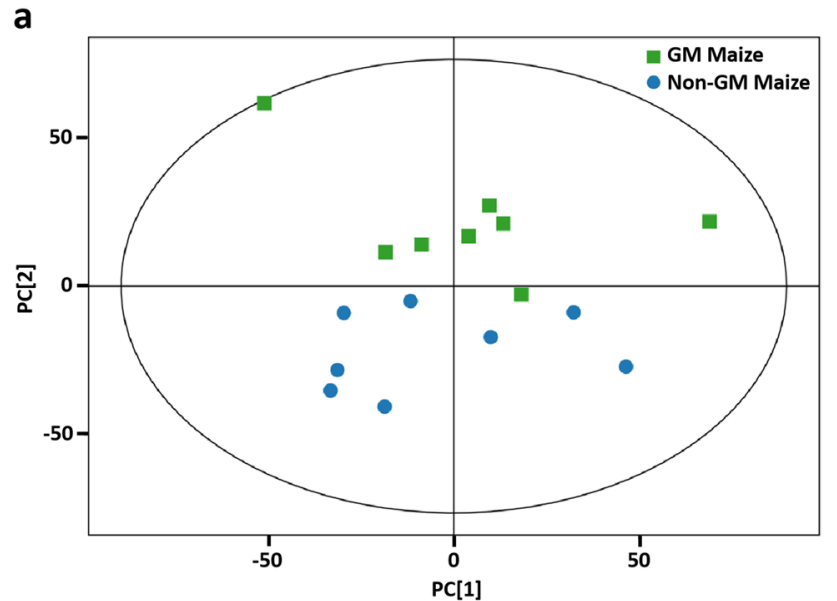

b

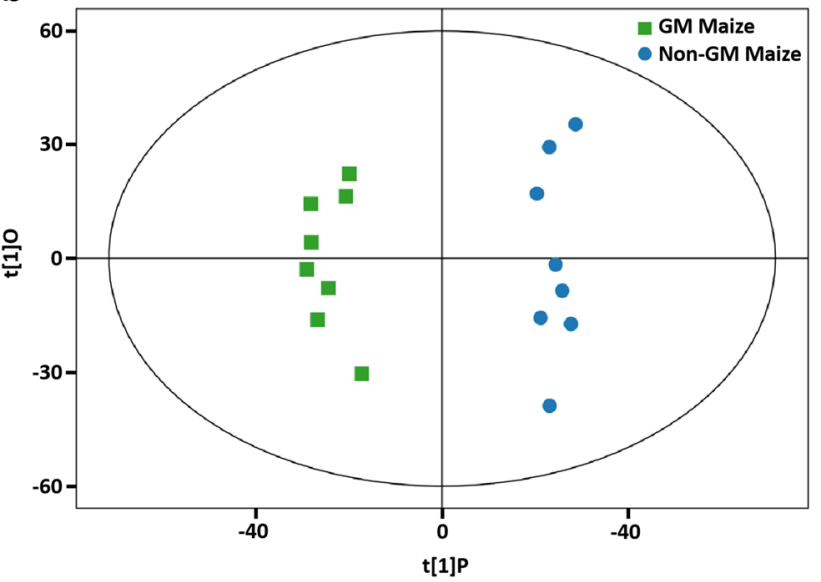

C

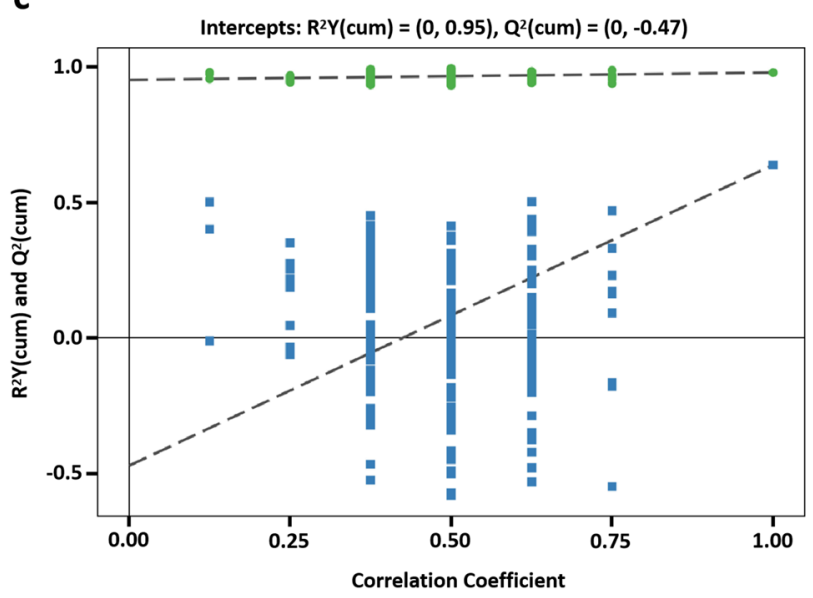

Fig. 5 Differential metabolites analysis in GM and non-GM maize. a Score plot from PCA model. b Score plot from OPLS-DA model. c Corresponding validation plot from OPLS-DA model. Correlation coefficient as the $\mathrm{X}$-axis represents the replacement reservation degree of replacement test, and the y-axis represents the value of $R^{2} Y$ (green dots) and $Q^{2}$ (blue square dots). The two dashes represent the regression lines of $R^{2} Y$ and $Q^{2}$, respectively
It is essential that GM plants should be evaluated and compared with their non-GM counterparts to ensure that the inserted sequence and the corresponding output do not negatively impact their food safety and nutritional equivalence (Ricroch et al. 2011). In this context, several studies have been conducted to investigate the unintended effect of GM plants using transcriptomics and metabolomics as evaluation criteria. Barros et al. (2010) identified that in glyphosate-tolerant transgenic maize, the alterations resulted from genetic modification in the levels of transcript, and protein and metabolite were fewer than those caused by environmental factors. Kim et al. (2013) found that the carotenoid-biofortified transgenic rice is substantially equivalent to its conventional counterpart at metabolic level. Rao et al. (2016) compared the metabolic changes in transgenic maize over-expressing the Aspergillus niger phyA 2 with its non-transgenic counterpart. They found that when natural variation was taken into consideration, the differential metabolites were only resulted from the target-engineered pathway in transgenic maize. Overall, all these former studies shed light on the biosafety of GM plants without unintended alteration in the cellular circumstance.

Although several researches have addressed the positive risk assessment of RNAi-based GM crops, the results are limited to ecological effects (Wolt et al. 2010; Bachman et al. 2016). To date, there is no report evaluating the safety of RNAi-based GM crops at the levels of transcriptome and metabolome. In this study, by integrating transcriptomics and metabolomics analysis, we revealed that there were only one gene and eight metabolites differentially expressed in MhSnf7 GM maize. According to the report by Christ et al. (2017), transgenic BAR indeed converts plant endogenous aminoadipate and tryptophan to their respective $\mathrm{N}$-acetylated products in several plant species. Our metabolomics data (Table S1) identified 172 compounds with known identity. However, the results did not cover the ectopic accumulation of acetyl-aminoadipate and acetyl-tryptophan from the non-specific $\mathrm{N}$-acetyltransferase activities of transgenic BAR acting upon plant endogenous amino acids. These data offer unambiguous evidences that MhSnf7 GM maize was almost identical to the non-GM equivalent. Therefore, our results expand current understanding of the transcriptome and metabolome changes in RNAi-based GM crops. We expect that this study could be used as a proper reference for evaluating the risk assessment of GM crops and ultimately benefit agricultural production in China. 
Table 4 The differentially expressed metabolites between MhSnf7 GM and non-GM maize

\begin{tabular}{llllll}
\hline ID & MS2 name & MS2 score & VIP value & FDR value & $\log _{2}$ fold change \\
\hline 4949 & Null & Null & 2.1225 & 0.0412 & -2.7261 \\
3710 & Null & Null & 2.1832 & 0.0412 & -1.9935 \\
3628 & Null & Null & 2.4867 & 0.0461 & -0.7954 \\
3266 & Null & Null & 2.4709 & 0.0498 & -0.7137 \\
2002 & Null & Null & 2.5289 & 0.0412 & -0.6673 \\
110 & Gamma-Butyrolactone & 0.5057 & 2.3865 & 0.0412 & 0.8481 \\
2608 & Null & Null & 2.4935 & 0.0412 & 0.9032 \\
4083 & Null & Null & 2.5038 & 0.0412 & 1.0089 \\
\hline
\end{tabular}

Fig. 6 Volcano plot analysis for differential metabolite expression. $\log _{2}$ Fold change as the $\mathrm{x}$-axis represents the multiple change of each metabolite and $-\log _{10}$ (FDR-value) from the $t$ test as the y-axis. The significantly up-regulated metabolites are shown in red, while the significantly down-regulated metabolites are shown in blue, and the non-significantly different metabolites are shown in gray. The dots size represents the VIP value of the OPLS-DA model, and the larger the dot, the greater the VIP value

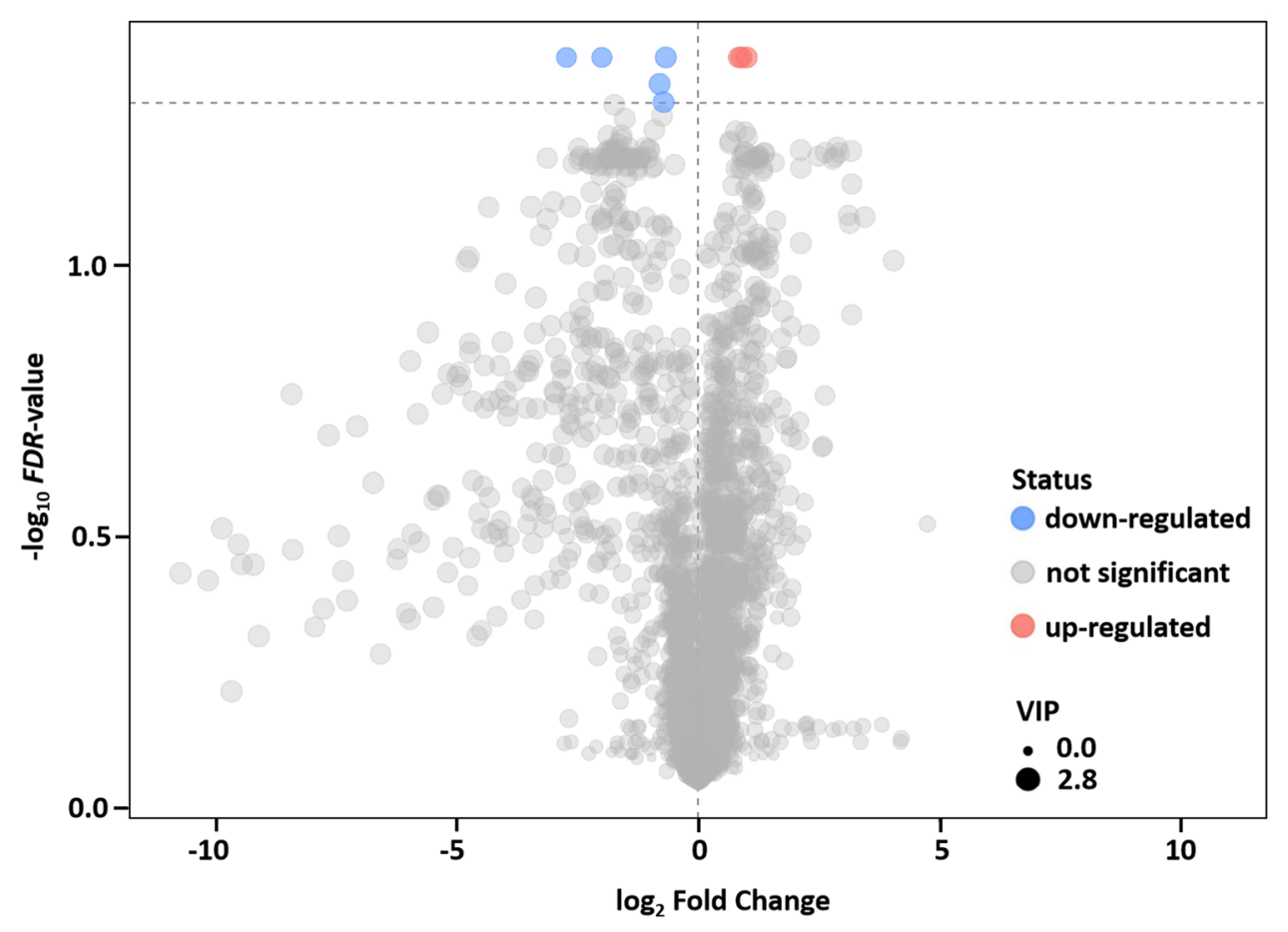

Acknowledgements This work was supported by grants from the Major Project of China on New Varieties of GMO Cultivation (2018ZX08011-04B). The data analysis was assisted by Biotree Biotech Co., Ltd. (Shanghai, China).

Author contribution statement $\mathrm{XZ}, \mathrm{HW}$ and RZ conceived and designed the research. LL, YY, YD, HG, XW and AZ conducted the experiments. $\mathrm{XZ}$ analyzed the data and wrote the manuscript. All authors read and approved the manuscript.

\section{Compliance with ethical standards}

Conflict of interest The authors declare that they have no conflict of interest.

Open Access This article is licensed under a Creative Commons Attribution 4.0 International License, which permits use, sharing, adaptation, distribution and reproduction in any medium or format, as long as you give appropriate credit to the original author(s) and the source, provide a link to the Creative Commons licence, and indicate if changes were made. The images or other third party material in this article are included in the article's Creative Commons licence, unless indicated otherwise in a credit line to the material. If material is not included in the article's Creative Commons licence and your intended use is not permitted by statutory regulation or exceeds the permitted use, you will need to obtain permission directly from the copyright holder. To view a copy of this licence, visit http://creativecommons.org/licenses/by/4.0/.

\section{References}

Abdullah HM, Chhikara S, Akbari P, Schnell DJ, Pareek A, Dhankher OP (2018) Comparative transcriptome and metabolome analysis suggests bottlenecks that limit seed and oil yields in transgenic Camelina sativa expressing diacylglycerol acyltransferase 1 and glycerol-3-phosphate dehydrogenase. Biotechnol Biofuels 11(1):335-376. https://doi.org/10.1186/s1306 8-018-1326-2

Bachman PM, Bolognesi R, Moar WJ, Mueller GM, Paradise MS, Ramaseshadri P, Tan J, Uffman JP, Warren J, Wiggins BE, Levine SL (2013) Characterization of the spectrum of insecticidal activity of a double-stranded RNA with targeted activity against 
Western Corn Rootworm (Diabrotica virgifera virgifera LeConte). Transgenic Res 22(6):1207-1222. https://doi.org/10.1007/s1124 8-013-9716-5

Bachman PM, Huizinga KM, Jensen PD, Mueller G, Tan J, Uffman JP, Levine SL (2016) Ecological risk assessment for DvSnf7 RNA: a plant incorporated protectant with targeted activity against western corn rootworm. Regul Toxicol Pharmacol 81:77-88. https:// doi.org/10.1016/j.yrtph.2016.08.001

Bagri DS, Upadhyaya DC, Kumar A, Upadhyaya CP (2018) Overexpression of PDX-II gene in potato (Solanum tuberosum L.) leads to the enhanced accumulation of vitamin B6 in tuber tissues and tolerance to abiotic stresses. Plant Sci 272:267-275. https://doi. org/10.1016/j.plantsci.2018.04.024

Barros E, Lezar S, Anttonen MJ, Van Dijk JP, Röhlig RM, Kok EJ, Engel KH (2010) Comparison of two GM maize varieties with a near-isogenic non-GM variety using transcriptomics, proteomics and metabolomics. Plant Biotechnol J 8(4):436-451. https://doi. org/10.1111/j.1467-7652.2009.00487.x

Baum JA, Bogaert T, Clinton W, Heck GR, Feldmann P, Ilagan O, Johnson S, Plaetinck G, Munyikwa T, Pleau M, Vaughn T, Roberts J (2007) Control of coleopteran insect pests through RNA interference. Nat Biotechnol 25(11):1322-1326. https://doi.org/10.1038/ nbt1359

Bolognesi R, Ramaseshadri P, Anderson J, Bachman P, Clinton W, Flannagan R, Ilagan O, Lawrence C, Levine S, Moar W, Mueller G, Tan JG, Uffman J, Wiggins E, Heck G, Segers G (2012) Characterizing the mechanism of action of double-stranded RNA activity against western corn rootworm (Diabrotica virgifera virgifera LeConte). PLoS ONE 7(10):e47534. https://doi.org/10.1371/journ al.pone. 0047534

Chen GH, Yin W, Li Q, Hu HY (2016) Research progress on Monolepta hieroglyphica (Motschulsky). China Plant Prot 36(10):1926. https://doi.org/10.3969/j.issn.1672-6820.2016.10.004

China National Bureau of Statistics (2019) China statistical yearbook. http://www.stats.gov.cn/tjsj/ndsj/2019/indexch.htm

Christ B, Hochstrasser R, Guyer L, Francisco R, Aubry S, Hörtensteiner S, Weng JK (2017) Non-specific activities of the major herbicide-resistance gene BAR. Nature Plants 3:937-945. https:// doi.org/10.1038/s41477-017-0061-1

Darsan Singh JK, Mat Jalaluddin NS, Sanan-Mishra N, Harikrishna JA (2019) Genetic modification in Malaysia and India: current regulatory framework and the special case of non-transformative RNAi in agriculture. Plant Cell Rep 38(12):1449-1463. https:// doi.org/10.1007/s00299-019-02446-6

Environment WHOROfEECf, Health, ECEH RDWE (2000) Safety aspects of genetically modified foods of plant origin: report of a Joint FAO/WHO Expert Consultation on foods derived from biotechnology: WHO Headquarters, Geneva, Switzerland, 29 May-2 June 2000 | Clc. Geneva World Health Organization

Fu S, Liu ZX, Chen JZ, Sun GX, Jiang YX, Li MW, Xiong L, Chen SP, Zhou YP, Asad M, Yang G (2019) Silencing arginine kinase/ integrin $\beta 1$ subunit by transgenic plant expressing dsRNA inhibits the development and survival of Plutella xylostella. Pest Manag Sci. https://doi.org/10.1002/ps.5701[Epub ahead of print]

Gayen D, Paul S, Sarkar SN, Datta SK, Datta K (2016) Comparative nutritional compositions and proteomics analysis of transgenic $\mathrm{Xa} 21$ rice seeds compared to conventional rice. Food Chem 203:301-307. https://doi.org/10.1016/j.foodchem.2016.02.058

Harrigan GG, Chassy B (2012) Challenges for metabolomics as a tool in safety assessments. In: Roessner U (ed) Metabolomics. IntechOpen, London, pp 331-348

Hiei Y, Ohta S, Komari T, Kumashiro T (1994) Efficient transformation of rice (Oryza sativa L.) mediated by Agrobacterium and sequence analysis of the boundaries of the T-DNA. Plant J 6(2):271-282
Kim JK, Park SY, Lee SM, Lim SH, Kim HJ, Oh SD, Yeo Y, Cho HS, Ha SH (2013) Unintended polar metabolite profiling of carotenoid-biofortified transgenic rice reveals substantial equivalence to its non-transgenic counterpart. Plant Biotechnol Rep 7(1):121128. https://doi.org/10.1007/s11816-012-0231-6

Lambirth KC, Whaley AM, Blakley IC, Schlueter JA, Bost KL, Loraine AE, Piller KJ (2015) A comparison of transgenic and wild type soybean seeds: analysis of transcriptome profiles using RNAseq. BMC Biotechnol 15:89-106. https://doi.org/10.1186/s1289 6-015-0207-Z

Li GZ, Wu YF, Liu GY, Xiao XH, Wang PF, Gao T, Xu MJ, Han QX, Wang YH, Guo TC, Kang GC (2017) Large-scale proteomics combined with transgenic experiments demonstrates an important role of jasmonic acid in potassium deficiency response in wheat and rice. Mol Cell Proteomics 16(11):1889-1905. https:// doi.org/10.1074/mcp.RA117.000032

Li H, Ma DY, Ma JF (2016) A survey of the occurrence and research status of the leaf beetle of Motschulsky in Xinjiang. Xinjiang Agri Sci Technol 05:35-36. https://doi.org/10.3969/j. issn.1007-3574.2016.05.020

Liu X, Tian G, Wang FY, Li HX, Li ZH, Wang XY, Wang ZH, Wang GL, Wang YW (2016) A preliminary study on the dynamics of Motschulsky in the valley. Chinese Agri Sci Bull 21:177-180. https://doi.org/10.11924/j.issn.1000-6850.casb15120121

Luan YS, Cui J, Wang WC, Meng J (2016) Mir 1918 enhances tomato sensitivity to Phytophthora infestans infection. Sci Rep 6:3585835869. https://doi.org/10.1038/srep35858

Mao YB, Cai WJ, Wang JW, Hong GJ, Tao XY, Wang LJ, Huang YP, Chen XY (2007) Silencing a cotton bollworm P450 monooxygenase gene by plant mediated RNAi impairs larval tolerance of gossypol. Nat Biotechnol 25(11):1307-1313. https://doi.org/10.1038/ nbt 1352

Ni M, Ma W, Wang XF, Gao MJ, Dai Y, Wei XL, Zhang L, Peng YG, Chen SY, Ding LY, Tian Y, Li J, Wang HP, Wang XL, Xu GW, Guo WZ, Yang YH, Wu YD, Heuberger S, Tabashnik BE, Zhang TZ, Zhu Z (2017) Next-generation transgenic cotton: pyramiding RNAi and Bt counters insect resistance. Plant Biotechnol J 15(9):1204-1213. https://doi.org/10.1111/pbi.12709

Ning K, Ding CJ, Zhu WX, Zhang WX, Dong YF, Shen YB, Su XH (2018) Comparative metabolomic analysis of the cambium tissue of non-transgenic and multi-gene transgenic poplar (Populus $\times$ euramericana 'Guariento'). Front Plant Sci 9:1201-1212. https ://doi.org/10.3389/fpls.2018.01201

Peng C, Chen XY, Wang XF, Xu XL, Wei W, Wang CM, Xu JF (2018) Comparative analysis of miRNA expression profiles in transgenic and non-transgenic rice using miRNA-seq. Sci Rep 8(1):338-347. https://doi.org/10.1038/s41598-017-18723-x

Poreddy S, Li J, Baldwin IT (2017) Plant-mediated RNAi silences midgut-expressed genes in congeneric lepidopteran insects in nature. BMC Plant Biol 17(1):199. https://doi.org/10.1186/s1287 0-017-1149-5

Rao J, Yang L, Guo J, Quan S, Chen G, Zhao X, Zhang D, Shi J (2016) Metabolic changes in transgenic maize mature seeds over-expressing the Aspergillus niger phyA2. Plant Cell Rep 35(2):429-437. https://doi.org/10.1007/s00299-015-1894-6

Ricroch A, Bergé JB, Kuntz M (2011) Evaluation of genetically engineered crops using transcriptomic, proteomic, and metabolomic profiling techniques. Plant Physiol 155(4):1752-1761. https://doi. org/10.1104/pp.111.173609

Schiemann J, Dietz-Pfeilstetter A, Hartung F, Kohl C, Romeis J, Sprink $\mathrm{T}$ (2019) Risk assessment and regulation of plants modified by modern biotechniques: current status and future challenges. Annu Rev Plant Biol 70:699-726. https://doi.org/10.1146/annurev-arpla nt-050718-100025

Shen QQ, Pu QY, Liang J, Mao HJ, Liu J, Wang Q (2019) Cyp71z18 overexpression confers elevated blast resistance in transgenic rice. 
Plant Mol Biol 100(6):579-589. https://doi.org/10.1007/s1110 3-019-00881-3

Shi SS, Wang XQ, Tian J, Gao Y, Cui J, Zhu SY (2017) The occurrence dynamics and economic threshold of the adult of Motschulsky in soybean field. Chinese Oil Crop Sci 02:239-244. https://doi. org/10.7505/j.issn.1007-9084.2017.02.015

Van Emon JM (2016) The omics revolution in agricultural research. J Agric Food Chem 64(1):36-44. https://doi.org/10.1021/acs. jafc. 5 b04515

Vazquez F, Legrand S, Windels D (2010) The biosynthetic pathways and biological scopes of plant small RNAs. Trends Plant Sci 15(6):337-345. https://doi.org/10.1016/j.tplants.2010.04.001

Wang XJ, Zhang X, Yang JT, Wang ZX (2018) Effect on transcriptome and metabolome of stacked transgenic maize containing insecticidal cry and glyphosate tolerance epsps genes. Plant J 93(6):1007-1016. https://doi.org/10.1111/tpj.13825

Wolt JD, Keese P, Raybould A, Fitzpatrick JW, Burachik M, Gary A, Olin SS, Schiemann J, Sears M, Wu F (2010) Problem formulation in the environmental risk assessment for genetically modified plants. Transgenic Res 19:425-436. https://doi.org/10.1007/s1124 8-009-9321-9
Worley B, Powers R (2013) Multivariate analysis in metabolomics. Curr Metab 1(1):92-107. https://doi.org/10.2174/2213235X11 301010092

Yan Y, Liu T, Wang Y, Ma XX, Xu L, Li DN, Ma JH (2019) Investigation on main pests of sweet sorghum in Ningxia irrigation area. Modern Agri Sci Tech 11:96-99. https://doi.org/10.3969/j. issn.1007-5739.2019.11.058

Zhang J, Khan SA, Heckel DG, Bock R (2017) Next-generation insectresistant plants: RNAi-mediated crop protection. Trends Biotechnol 35(9):871-882. https://doi.org/10.1016/j.tibtech.2017.04.009

Zhou J, Zhang L, Li X, Chang YW, Gu Q, Lu X, Zhu Z, Xu GW (2012) Metabolic profiling of transgenic rice progeny using gas chromatography-mass spectrometry: the effects of gene insertion, tissue culture and breeding. Metabolomics 8:529-539. https://doi. org/10.1007/s11306-011-0338-8

Publisher's Note Springer Nature remains neutral with regard to jurisdictional claims in published maps and institutional affiliations. 